\title{
REDDITI TURCHI ET POTENTIARUM NOBIS. UN NUEVO TESTIMONIO SOBRE LA CRUZADA CONTRA EL IMPERIO OTOMANO A MEDIADOS DEL SIGLO XV
}

\author{
REDDITI TURCHI ET POTENTIARUM NOBIS. \\ NEW EVIDENCE CONCERNING ON THE CRUSADE AGAINST \\ THE OTTOMAN EMPIRE IN THE MID FIFTEENTH CENTURY
}

\author{
MERCEDES LÓPEZ-MAYÁN \\ Universidade da Coruña \\ http://orcid.org/0000-0002-9671-1127
}

\begin{abstract}
Resumen: El examen del códice litúrgico 56-23 de la Biblioteca Capitular de Toledo ha revelado la existencia de un texto de excepcional riqueza, hasta ahora ignorado por los investigadores, que recoge una exhaustiva valoración de la capacidad económica y militar del Turco y de las potencias cristianas, así como de sus virtudes y defectos en combate. A través del análisis de su contenido y de su materialidad, este artículo vincula las circunstancias de origen y uso de dicho escrito con los preparativos del proyecto bélico que Pío II emprendió contra el Imperio otomano en 1458 y lo contextualiza e interpreta en el seno de las numerosas creaciones literarias de cruzada que proliferaron en la Europa humanista tras la conquista otomana de Constantinopla en 1453.
\end{abstract}

Palabras clave: proyectos de cruzada; Imperio otomano; Pío II; siglo XV.

\begin{abstract}
The examination of liturgical codex 56-23 in Toledo Cathedral Library has revealed the existence of an exceptionally rich text, hitherto overlooked by researchers. This document contains an exhaustive assessment of the economic and military capabilities of the Turks and the Christian powers, as well as a description of their strengths and weaknesses in combat. Through the analysis of its contents and its materiality, on the one hand this article associates the circumstances of its origin and use with the preparations for the crusading project that Pius II organized against the Ottoman Empire in 1458. On the other it contextualizes and interprets this new evidence as one of the numerous crusading treatises that proliferated in humanist Europe after the Ottoman conquest of Constantinople in 1453.
\end{abstract}

Keywords: crusading projects; Ottoman Empire; Pius II; 15th century.

\section{SUMARIO}

1. Un informe en un año decisivo: 1458.- 2. Redditi, impensae et equitum: fuentes y discursos.- 3. ¿En un manuscrito litúrgico? Acerca del códice 56-23.- 4. Un informe para la cruzada de Pío II.- 5. Bibliografía citada.- 6. Apéndice documental. 
La conquista de Constantinopla por el Imperio otomano en 1453, con la consiguiente irrupción en territorio europeo de una nueva y amenazante potencia militar, causó un impacto sin precedentes en la situación política y económica del Occidente cristiano, así como en su conciencia religiosa y en los pilares que fundamentaban su identidad cultural ${ }^{1}$. Una de las consecuencias de este fenómeno fue la eclosión de un subgénero literario que, si bien existía desde finales del siglo XIII², alcanzó su máximo apogeo en el seno de la historiografía humanista de la segunda mitad del Cuatrocientos. Se trata de la, en ocasiones denominada, literatura de cruzada, término bajo el cual se esconde una gran variedad tipológica de textos, desde informes técnicos y proyectos de guerra hasta ensayos históricos y literarios, pasando por invocaciones, oraciones, cartas, etc., elaborados por autores de diversa condición y en distintas lenguas y formatos, pero dotados de un objetivo común: favorecer el conocimiento en Occidente de la realidad histórica, las características y la capacidad-sobre todo, militar y financiera- del Imperio otomano en aras de preparar una respuesta armada eficaz, capaz de poner freno al expansionismo turco en el Este europeo ${ }^{3}$. Como es bien sabido, tales esfuerzos retóricos, técnicos y diplomáticos resultaron insuficientes y no evitaron que la historia de la cruzada $-\mathrm{o}$, mejor dicho, de los proyectos de cruzada- contra el Turco en el siglo XV fuera, en fin, la historia de un fracaso motivado por la incapacidad de las potencias cristianas de concretar una expedición militar común ${ }^{4}$.

Aunque, desde la contribución pionera realizada por Nicolas Iorga a comienzos del $\mathrm{XX}^{5}$, han sido numerosos los productos de esta literatura de la cruzada tardía que se han descubierto y publicado ${ }^{6}$, la propia naturaleza de estos textos, esencialmente práctica, frecuentemente breve y plasmada sobre soportes perecederos, ha favorecido su desaparición o, en su defecto, su dispersión en archivos de todo el mundo. En este sentido, la Biblioteca Capitular de Toledo conserva un nuevo testimonio que hasta la fecha había pasado to-

\footnotetext{
${ }^{1}$ Una reciente síntesis general sobre la conquista de Constantinopla y sus efectos en Occidente puede consultarse en Nicolle, Turnbull, Haldon 2007.

${ }^{2}$ Paviot 2008.

${ }^{3}$ La literatura sobre esta cuestión es muy amplia, pero continúa siendo imprescindible la consulta de los trabajos pioneros de Pertusi 1970, 1974a. Para un balance historiográfico más reciente, véanse Albanese 2008, pp. 320-330; Housley 2013, pp. 2-6; Paviot 2014a.

${ }^{4}$ Weber 2013a, pp. 519-531. Sobre el concepto de cruzada en el siglo XV o cruzada tardía véanse Housley 1992; Paviot 2014b.

${ }^{5}$ Iorga 1899-1916.

${ }^{6}$ Entre otros, véanse, además de los citados en las notas precedentes, los trabajos de Pertusi 1974b, 1977; Hankins 1995; Weber 2013a, pp. 535-537.
} 
talmente inadvertido a los especialistas por haber sido copiado en los últimos folios de un manuscrito litúrgico, el 56-237.

Compuesto por doscientos veintisiete folios de $305 \times 215 \mathrm{~mm}$ realizados en vitela de gran calidad, este códice nunca había sido objeto de un estudio pormenorizado ${ }^{8}$, en gran medida a causa de la complejidad de su texto, que presenta carácter facticio y misceláneo. La primera parte, la más larga (ff. 1r-204v) y escrita por una única mano en gótica antiqua ${ }^{9}$, contiene la mayor parte de los ordines del llamado pontifical de Guillermo Durando ${ }^{10}$ y estaba, por tanto, destinada a ser utilizada por un obispo en el desarrollo de sus funciones litúrgicas ${ }^{11}$. A partir del f. 205r, sin embargo, se observa la intervención de dos manos posteriores, de formato humanístico, que añadieron sendos textos de naturaleza bien distinta: el opúsculo titulado Descriptio basilicae Vaticanae (ff. 205r-220v), originalmente compuesto por Petrus Mallius, canónigo de San Pedro, en tiempos de Alejandro III (1159-1181) y destinado a describir la topografía eclesiástica de la ciudad de Roma ${ }^{12}$; y un listado de las Indulgentie ecclesiarum urbis Rome (ff. 221r-225r) ${ }^{13}$. El manuscrito terminaba originalmente en el f. 225r, quedando los ff. 225v-227v en blanco. Éste fue el soporte utilizado por una cuarta mano, posterior y de perfil mucho más cursivo que las anteriores ${ }^{14}$, para incorporar el texto que nos ocupa. Bajo el título Redditus potentiarum nobis notarum et eorum potentiae in bellis, ofrece, en síntesis, una lista de los ingresos y gastos anuales del Turco y de las potencias cristianas, así como una relación de su capacidad militar, valorada en función del número de caballeros (equitum) que podían movilizar tanto dentro como fuera de sus respectivas fronteras. En las páginas que siguen y junto a la edición del propio texto ${ }^{15}$, abordaré su análisis con el objetivo de determinar cuándo y dónde se redactó, por quién o, en su defecto, en qué contexto y

\footnotetext{
${ }^{7}$ Un estudio detallado de este manuscrito puede verse en nuestro artículo, López Mayán en prensa, de próxima publicación.

${ }^{8}$ Tan solo aparece mencionado en algunos catálogos generales que no aclaran cuándo y dónde se confeccionó ni cuáles fueron su uso y su trayectoria. Véanse especialmente Janini, Gonzálvez 1977, pp. 228-237; Kay 2007, p. 182.

${ }^{9}$ Derolez 2006, pp. 176-182.

${ }^{10}$ Andrieu 1940.

${ }^{11}$ Sobre la naturaleza y características de los pontificales, véase López-Mayán 2012.

${ }^{12}$ Este opúsculo fue editado a partir de otros testimonios -y no del manuscrito que nos ocupa- por Valentini, Zucchetti 1940-1953, vol. III, pp. 375-442.

${ }^{13}$ Se trata de un género también conocido y del que han quedado múltiples testimonios, pues, a partir de la celebración del primer jubileo de Roma en 1300, fue habitual entregar este tipo de textos a los peregrinos que llegaban a la ciudad, junto con extractos de los Mirabilia o de otras descripciones de la urbe, Valentini, Zucchetti 1940-1953, vol. IV, p. 75.

${ }^{14}$ Presenta, además, ciertos rasgos peculiares, como el uso de la "e" caudata para representar el diptongo "ae".

${ }^{15} \mathrm{C} f$. apéndice documental.
} 
con qué finalidad fue compuesto, por qué se añadió en los folios finales de un manuscrito litúrgico con cuyo contenido no presenta -al menos, aparentemente- ninguna relación y, en definitiva, cuál es la importancia de este hallazgo en este amplio y variado subgénero historiográfico vinculado con la cruzada contra el Imperio otomano en la segunda mitad del siglo XV.

\section{UN INFORME EN UN AÑO DECISIVO: 1458}

$\mathrm{Al}$ igual que la mayoría de los testimonios ya $\operatorname{conocidos}^{16}$, el texto conservado en el manuscrito 56-23 de la Biblioteca Capitular de Toledo ofrece una descripción detallada de la capacidad -económica y militar- y de las fortalezas y debilidades tanto del Imperio otomano como de las potencias occidentales con la intención de valorar las opciones cristianas de triunfar en un eventual enfrentamiento armado. A tal efecto, su autor estructuró la información en dos grandes bloques. El primero, de carácter más cuantitativo, consiste en una serie de listados en los que, contabilizados en ducados de oro, se enumeran los ingresos (redditi) y los gastos (impensae) anuales de los estados integrantes de cada bando; además, se indica también el número de caballeros que cada uno de ellos podía movilizar tanto dentro como fuera de sus respectivas fronteras ${ }^{17}$. El segundo, por el contrario, se compone de una serie de apreciaciones más cualitativas acerca de las ventajas e inconvenientes que, en el campo de batalla, se derivan de la forma de ser, el comportamiento e, incluso, las actitudes morales de ambas culturas ${ }^{18}$. Termina el texto con una exhortación al consenso y la cooperación entre las potencias cristianas de Occidente para poner frento a la amenaza turca ${ }^{19}$.

Ahora bien, pese a ese ideario de fondo, común a otros testimonios conocidos y que examinaremos con más detalle en el siguiente apartado, el texto del códice 56-23 presenta una notable peculiaridad en su forma: no se trata de un proyecto de cruzada propiamente dicho en el sentido de que no contiene una exposición ordenada y concreta de la estrategia bélica más aconsejable ni de los argumentos y los objetivos que la justificaban; en realidad, nos hallamos ante unos apuntes -incluso en lo que se refiere al escaso cuidado con que están escritos-que, a modo de informe técnico, parecen haber sido confeccionados y, muy posiblemente, también utilizados con la perspectiva de preparación de una cruzada. Pero, ¿cuándo, por quién y en qué contexto?

\footnotetext{
${ }^{16} C f$. nota 6 .

${ }^{17} \mathrm{Cf}$. apéndice, párrafos 1-18.

${ }^{18} C f$. apéndice, párrafos 19-22.

${ }^{19} \mathrm{Cf}$. apéndice, párrafo 23 .
} 
El primer paso para desentrañar su sentido consiste en determinar el momento en que fue compuesto. El propio texto nos da la clave hacia el final, en el f. $227 \mathrm{v}$, cuando, al comentar las commoditates Turchorum contra fideles, el autor afirma:

Solus ipse cccc milia equitum gubernabit, / est non doctus et ad id agendum promptus videtur hoc illi sturpi innatum essere ac naturale / ut sapienter imperent hic sane Mahmetus disciplinam militarem ab anno aetatis suae / duodecimo ingressus semper usque in praesentem diem exerciut henbatque nunc annos sex et $\mathrm{xx}^{\mathrm{ti}}{ }^{20}$.

Se trata de una alusión a Mehmed II el Conquistador, emperador entre 1451 y 1481 y responsable de la primera gran expansión territorial del poder otomano. Tal y como se describe en el texto, en 1444, cuando tenía doce años, quedó como regente del Imperio otomano mientras su padre, Murad II (1421-1451), marchaba a Anatolia a sofocar los ataques del beylik karamánida Ibrahim II (m. 1464). A su vuelta, Murad abdicó en Mehmed, que, así, se convirtió en emperador a esa joven edad ${ }^{21}$. La referencia a que in praesentem diem tiene veintiséis años nos sitúa, por tanto, en 1458, en pleno contexto de la campaña otomana en territorio balcánico para abrirse paso hacia el Occidente europeo ${ }^{22}$.

Tal datación a partir de esa referencia explícita queda corroborada en otro pasaje precedente, en el que se indica que en ese año doscientos mil de los cuatrocientos mil jinetes que los otomanos podían movilizar se hallaban apostados en el Danubio, es decir, en la frontera del Imperio, mientras que otros cien mil se habían establecido en Tesalónica para garantizar la tutela del territorio y facilitar el avance ${ }^{23}$. En realidad, este fragmento ofrece una instantánea de los inicios de la campaña de Mehmed en los Balcanes en 1458. Tras un primer intento fallido en el sitio de Belgrado $(1456)^{24}$, el Conquistador encontró en el impago del tributo impuesto al Despotado de Morea desde 1457 la coartada para partir de Adrianópolis -actual Edirne- con un gran ejército reclutado en Asia Menor y llegar hasta Tesalia. Allí acampó varios días a la espera de refuerzos y con la intención de dar al Despotado una última oportunidad de saldar su deuda. Al no producirse tal reacción, la armada otomana atravesó el paso de las Termópilas -referido en el texto como duo montes

\footnotetext{
${ }^{20} C f$. apéndice, párrafo 21 .

${ }^{21}$ Freely 2009, pp. 13-15. Sobre la figura de Mehmed II continúa siendo imprescindible la consulta de los clásicos trabajos de Inalcik 1960; Babinger 1978.

${ }^{22}$ Shaw 1976, pp. 55-70; Fine 1987, pp. 453-612. Sobre la progresiva integración de los Balcanes en el Imperio otomano véanse, asimismo, Inalcik 1993; Kiel 2009; Orlando 2009.

${ }^{23} \mathrm{Cf}$. apéndice, párrafo 17 .

${ }^{24}$ Véase al respecto Fodor 2008.
} 
Graeciam dividentes-, bordeó el lago Copais y acampó en Beocia, en el valle del río Asopo, uallis latitudinis milium passuum xviii. A punto de retomar el avance, llegaron varios legados de Morea portando cuatro mil quinientos ducados, que Mehmed aceptó a cambio de la paz. Así se mantuvo la situación hasta el final del año, cuando Mehmed envió a Demetrio la petición de que su única hija, Helena, se casara con él o, en caso contrario, atacaría. Ante su negativa, comenzó la invasión militar que concluyó con la conquista del Despotado en $1461^{25}$.

No sorprende, pues, que, compuesto en 1458, el texto todavía incluya a Morea entre las potencias cristianas que aún conservaban su autonomía política, pese a estar sometidas a una creciente dependencia con respecto al Imperio otomano. Y lo mismo puede decirse del señorío de Mitilene ${ }^{26}$, que no caería en manos turcas hasta 1462, y de Albania, Croacia-Eslavonia, Serbia y Bosnia, que, a la altura de 1458, mantenían su independencia pero a costa de pagar un tributo económico y militar que los debilitaba internamente al tiempo que fortalecía al Turco ${ }^{27}$. De hecho, en el texto se alude de manera explícita al Bosnae comitis Stephani, esto es, al rey bosnio Stjepan Tomaš (1443-1461), un caso paradigmático de esa estrategia otomana de expansión, en la que, tras haber conseguido el sometimiento vasallático -en el caso de Bosnia, en 1458-, la negativa cristiana a pagar el tributo debido era utilizada por el Turco como pretexto para desencadenar la intervención militar que terminaba con la independencia del estado ${ }^{28}$.

Finalmente, la datación del texto en 1458 es también coherente con la situación geopolítica de Asia Menor, reflejada implíticamente a través de la nómina de dominios que se incluyen en uno u otro bando. En el caso de las potencias cristianas, se alude a la contribución del imperator Trapezundae ${ }^{29}$, es decir, de Trebisonda, el último baluarte del Imperio bizantino en la región, que no fue conquistado por los otomanos hasta 1461 y que, en consecuencia, a la altura de 1458 engrosaba la lista de los estados fideles $^{30}$. Por su parte, al contabilizar la capacidad económica y militar del Turco se tienen en cuenta las aportaciones de los beyliks o emiratos de Caramannus, Caraisanus, Tamborlanus, Carailef y Jamsa que, en su condición de vasallos del Otomano, debían contribuir cada año a la formación del ejército del Imperio con una

\footnotetext{
${ }^{25}$ Setton 1978, pp. 197-199; Freely 2009, pp. 63-73. Sobre la conquista otomana de Morea véase también Shawcross 2009.

${ }^{26} C f$. apéndice, párrafo 16 .

${ }^{27} \mathrm{Cf}$. apéndice, párrafo 7.

${ }^{28}$ Pitcher 1972, pp. 90-91.

${ }^{29} \mathrm{Cf}$. apéndice, párrafo 16 .

${ }^{30}$ Karpov 1986, pp. 29-69.
} 
aportación de caballeros financiados, a su vez, gracias al cobro del vectigal ${ }^{31}$. Indirectamente el texto constata, pues, que tales emiratos todavía conservaban su entidad política propia, que, de hecho, desaparecería progresivamente entre 1461 y 1472, cuando Mehmed II los integró por completo en sus dominios ${ }^{32}$.

Resulta, pues, claro que este informe técnico destinado a la preparación de una eventual cruzada fue compuesto en un año decisivo, 1458, en el que la inminencia y gravedad de la amenaza otomana eran una realidad en el Este europeo. Pero, además, de las características de su grafía se deduce que el testimonio material que hoy se conserva en el manuscrito 56-23 fue escrito en ese mismo año o, a lo sumo, muy poco tiempo después. Así lo indica su identidad formal con la escritura que presenta el códice Vat. lat. 15178 de la Biblioteca Apostolica Vaticana, realizado en Roma entre 1457 y 1463 y que contiene las Recollectae de Pietro Odo da Montopoli, inicialmente elaboradas como apuntes sueltos y después encuadernadas en un solo volumen ${ }^{33}$. Este paralelo gráfico reviste una gran importancia porque, por un lado, permite afirmar que nuestro texto es un testimonio coetáneo de los hechos que describe, circunstancia excepcional dentro de la literatura de cruzada que, con frecuencia, se ha conservado en copias o traslados de cronologías posteriores. Y, por otro, constituye un argumento a favor de la hipótesis -sobre la que volveremos más adelante- de que este fragmento es un borrador, confeccionado, posiblemente en Roma, ante unas determinadas necesidades de uso inmediato, aprovechando los folios finales en blanco de un manuscrito y sin ningún interés por dotarlo de un formato cuidado.

\section{REDDITI, IMPENSAE ET EQUITUM: FUENTES Y DISCURSOS}

Aunque redactado en primera persona ${ }^{34}$, nuestro escrito presenta carácter anónimo. No ofrece, pues, ningún dato acerca de la identidad de su autor, más allá de su condición cristiana, patente en la referencia sistemática a los otomanos como infideles, la invocación final ${ }^{35} \mathrm{y}$, obviamente, su inclusión en los últimos folios de un manuscrito litúrgico. Su análisis interno tampoco resulta esclarecedor puesto que no existe ningún paralelo preciso entre su texto y el de otros ejemplos de literatura de cruzada, precedentes o coetáneos, de autoría conocida. Por su cercanía cronológica son especialmente signficati-

\footnotetext{
${ }^{31} C f$. apéndice, párrafo 2.

${ }^{32}$ Pitcher 1972, pp. 77-79; Manz 2005, pp. 86-93, 115-136.

${ }^{33}$ Caldelli 2006, p. 195.

${ }^{34} \mathrm{Cf}$. apéndice, párrafo 11 .

${ }^{35} \mathrm{C} f$. apéndice, párrafo 23 .
} 
vos el Strategicon adversum Turcos de Lampo Birago (c. 1453-1455) ${ }^{36}$, el De origine et gestis Turcarum liber, compuesto por Nicola Segundo en 1456 por encargo de Eneas Silvio Piccolomini, entonces obispo de Siena ${ }^{37}$, las epístolas escritas por el humanista Lauro Quirini entre 1453 y 1470 y entre las que se incluye una enviada en 1458 al cardenal Ludovico Trevisan-Scarampo ${ }^{38}$, los Constantinopoleos libri IV de Ubertino Pusculo de Brescia, dedicados a Pío II y redactados entre 1458 y $1464^{39}$, y la Oratio de assumptione beatae Mariae virginis Mantuae in sacello summi pontificis, escrita por Niccolò Perotti el 15 de agosto de 1458 e integrada en un sermón que posiblemente él mismo pronunció ante la asamblea de Mantua del año siguiente ${ }^{40}$.

Ninguno de estos humanistas es el autor de nuestro testimonio y ninguna de estas obras parece haber sido utilizada como fuente para su composición ya que, además de no presentar ningún pasaje textualmente idéntico o similar, las estimaciones numéricas que ofrece acerca de las finanzas y la capacidad militar del Turco difieren, como veremos, de las referidas en los citados escritos. Ciertamente, el artífice del texto que nos ocupa podría haber empleado otras fuentes que hoy no se conservan o que todavía no han sido descubiertas, pero tampoco se ha de descartar la posibilidad de que hubiera mantenido algún tipo de contacto directo con la realidad otomana, circunstancia habitual entre muchos de los autores de la literatura de cruzada, que, en última instancia, explica el profundo y conciso conocimiento que el Occidente cristiano poseyó sobre el Imperio turco a lo largo del siglo $\mathrm{XV}^{41}$.

Ahora bien, el fragmento del manuscrito 56-23 sí que comparte con las obras referidas una serie de características comunes, tanto en los aspectos del Otomano a los que se concede especial atención, como en el discurso y la ideología de cruzada que subyacen en ellos. Esta circunstancia no resulta sorprendente porque se trata de una literatura frecuentemente redundante, nacida en un mismo ambiente y con un mismo ideario, pero tiene la virtud de favorecer la contextualización de este nuevo testimonio.

El elemento desencadenante de la confección misma del texto y del resto de obras aludidas es, lógicamente, la grave y acuciante amenaza que para las potencias cristianas representaba el Imperio otomano y, sobre todo, su avance en el Este europeo tras la conquista de Constantinopla. La defensa frente a tal situación, evocada en nuestro caso a través de la alusión a las

\footnotetext{
${ }^{36}$ Pertusi 1974b.

${ }^{37}$ Pertusi 1970, pp. 471-477.

${ }^{38}$ Pertusi 1977.

${ }^{39}$ Ellissen 1857, pp. 1-83.

${ }^{40}$ Hankins 1995, pp. 147-207.

${ }^{41}$ Sobre esta cuestión véase Fleet 2000, pp. 99-112.
} 
fuerzas apostadas en la Península Balcánica, pasaba necesariamente por la promoción de una cruzada, razón última de la existencia de esta literatura. Su éxito requería, a su vez, de varios ingredientes que están bien representados en el documento que analizamos.

En primer lugar, se precisaba de la creación de una imagen del enemigo, que, en el siglo XV, combinó los característicos topoi anti-islámicos -infidelidad, barbarie, violencia contra los cristianos, etc.- con nuevas ideas, de inspiración humanista, relacionadas con la visión del Turco como rival no solo religioso, sino también, y sobre todo, político y cultural ${ }^{42}$. El autor de nuestro texto participa de este ideario puesto que, por una parte, alude a los otomanos como infideles, calificativo bajo el que subyace toda una tradición de pensamiento cristiano acerca del carácter herético de la religión islámica ${ }^{43}$, pero, al mismo tiempo, no ahonda en disquisiciones religiosas y, de hecho, solo implícitamente se puede entender su condición de infieles como la causa de la bajeza moral que se manifiesta en su gusto por el lujo, en su molicie y en sus afeminados comportamientos ${ }^{44}$. Su objetivo es, sobre todo, describir el funcionamiento del gran engranaje turco para mostrar las commoditates Turchorum contra fideles, esto es, los numerosos beneficios que se derivan de él en contraste con la situación de las potencias occidentales.

Junto a algunas apreciaciones cualitativas ${ }^{45}$, su atención se centra en dos elementos principales, considerados como los más importantes en toda la literatura de cruzada: la situación financiera y la capacidad militar del Turco. En el primer caso, nuestro autor estima en un total de 7.780 .000 ducados de oro los ingresos anuales con que contaba la hacienda imperial, procedentes de los tributos directos que debían satisfacer tanto las familias cristianas residentes en sus dominios como los propios hogares musulmanes, de las tasas indirectas o vectigales que gravaban las transacciones comerciales y de los tributos que tenían que pagar los estados sometidos a vasallaje ${ }^{46}$. Por su parte, se indica que los gastos de la hacienda imperial ascendían a 6.567.000 ducados de oro, consumidos en dos grandes partidas: el mantenimiento del ejército, con particular atención a las unidades de infantería de los jenízaros ${ }^{47}$, y la importación de productos textiles destinados a cubrir las necesidades de la familia imperial y su entorno y procedentes mayoritariamente de Europa -aunque tam-

\footnotetext{
${ }^{42}$ Weber 2013a, pp. 444-480. Sobre la construcción de la imagen del Turco desde el humanismo cristiano, véanse también las recientes aproximaciones de Soykut 2001; Meserve 2004; Puig de la Bellacasa, Servantie 2005.

${ }^{43}$ Sabbatini 2010.

${ }^{44} C f$. apéndice, párrafo 23.

${ }^{45} C f$. apéndice, párrafo 22 .

${ }^{46} C f$. apéndice, párrafos 7-8.

${ }^{47} C f$. apéndice, párrafos 10-11.
} 
bién se alude a la adquisición de paños de sede de Bursa, enclave final de la Ruta de la Seda y base del desarrollo económico-comercial del Imperio- ${ }^{48}$. En conjunto, y con independencia de la mayor o menor veracidad de las cifras indicadas, resulta evidente que el autor de este texto: a) conocía en detalle el funcionamiento de la economía otomana, asentada sobre un estricto sistema impositivo $^{49}, \mathrm{y}$ b) pretendía llamar la atención sobre el superávit anual de la hacienda imperial, una de las razones de la fortaleza del Turco, frente a la incapacidad gestora de las potencias cristianas, sistemáticamente endeudadas ${ }^{50}$. Y, junto a su cualidad como eficaz gestor, se le describe también como una gran potencia militar, no solo desde el punto de vista cuantitativo, por su capacidad de movilizar a 1.150.000 jinetes ${ }^{51}$, sino también cualitativo, al hacer hincapié en la gobernabilidad de este gran ejército, consecuencia de la ausencia de divisiones internas y de su sometimiento a una única y diligente autoridad ${ }^{52}$. Aunque con distintas cifras, la importancia numérica de la armada otomana y la eficacia de su organización fue, de hecho, resaltada por todos los observadores cristianos como un mecanismo que, ante todo, pretendía incitarles a reaccionar ${ }^{53}$.

Junto al conocimiento del enemigo otomano, la promoción de la cruzada pasaba, en segundo lugar, por conseguir movilizar a las potencias cristianas y convencerlas de que destinaran una parte de sus recursos a la guerra contra el Turco. Con tal objetivo, el autor de nuestro texto traza una panorámica desoladora, aunque sucinta, de la realidad del Occidente europeo. En este caso, su propósito no es describir su organización y funcionamiento, perfectamente conocidos en el ámbito cristiano en que lo compuso, sino llamar la atención sobre las deficiencias que debían ser corregidas para poder alcanzar la victoria en ese futuro choque armado. Sobre todo, se lamenta de las enormes dificultades financieras que implicaba afrontar un proyecto de cruzada de estas características. Así, a través de un escueto balance de ingresos y gastos anuales de las distintas potencias, constata que todas ellas habían experimentado una reducción drástica de su poder económico en los últimos años como consecuencia de los múltiples conflictos en los que se habían visto inmersas,

\footnotetext{
${ }^{48} C f$. apéndice, párrafo 9.

${ }^{49}$ Para un estudio más detenido de esta cuestión, véanse Fleet 2009; Panaite 2000; Inalcik, Quataert 1994, pp. 55-76, 218-255.

${ }^{50} \mathrm{Cf}$. apéndice, párrafo 11 .

${ }^{51}$ De ellos, 400.000 eran el resultado del reclutamiento en los territorios directamente dominados por el Turco, mientras que los 750.000 restantes procedían de los emiratos de Asia Menor sometidos a vasallaje o de acuerdos de cooperación con otros estados islámicos de las costas mediterráneas, $c f$. apéndice, párrafo 2 .

${ }^{52} C f$. apéndice, párrafo 22 . Un estudio detallado sobre la estructura militar del Imperio otomano puede consultarse en Murphey 2010.

${ }^{53}$ Weber 2013a, pp. 481-482.
} 
lo que, obviamente, actuaba en detrimento de sus recursos en la guerra contra el Otomano ${ }^{54}$. Y no solo eso, sino que, además, esa pérdida de riqueza hacía que las haciendas cristianas vivieran en un déficit permanente, incapaz de hacer frente al capítulo de gastos que, solo en lo relativo a la adquisición de armamento, ascendía a $36.000 .000^{55}$.

Al margen de la cuestión de su veracidad -ciertamente dudosa-, bajo estas cifras se esconde una crítica a la realidad europea, que es común a todos los proyectos y creaciones literarias de cruzada actualmente conocidos. En este sentido, se ha señalado que, aunque efectivamente el coste de la cruzada contra el Otomano era elevado en la segunda mitad del XV por la mayor sofisticación de las armas y por el alejamiento de los frentes de batalla, su financiación no resultaba imposible, especialmente para la hacienda papal, responsable principal de estos proyectos ${ }^{56}$. Por tanto, el discurso de nuestro autor, al igual que el de sus contemporáneos, debe entenderse como un recurso retórico que pretendía movilizar la participación económica de todas las potencias en apoyo de la cruzada. Y lo mismo puede decirse de su capacidad militar, que tampoco resiste la comparación con el Imperio otomano: frente a los 1.150.000 jinetes que este era capaz de movilizar, los diversos estados europeos solo podían disponer de un máximo de 888.000 equitum $^{57}$, siempre y cuando todos ellos sumaran sus fuerzas y, además, aceptaran someterlas a una única autoridad ${ }^{58}$.

Todos los datos, pues, están expuestos en nuestro texto siguiendo una lógica deductiva que pretende llevar al lector -0 , más posiblemente, al oyente- de este informe a una conclusión, la tercera y última condición para la promoción de una cruzada exitosa: la necesidad de unión entre los poderes cristianos, el nationum consensus predicado por el propio papa Pío II en los prolegómenos de la reunión de Mantua de $1459^{59}$. Es decir, en vista del potencial del enemigo, era imprescindible que en esa futura cruzada los estados europeos se comprometiesen a unir sus fuerzas económicas y militares en pro del beneficio común ${ }^{60}$. Es más, para que tal unión fuera realmente operativa y no desembocase en un absoluto desgobierno, el mando último de ese ejército cristiano debería ser único. No se afirma explícitamente en el texto, pero puede sobreentenderse que dicho mando recaería en el propio pontífice, que,

\footnotetext{
${ }^{54} C f$. apéndice, párrafos 4-6.

${ }^{55} \mathrm{Cf}$. apéndice, párrafo 12 .

${ }^{56}$ Weber 2013a, pp. 259-276.

${ }^{57} C f$. apéndice, párrafos 13-16.

${ }^{58} C f$. apéndice, párrafos 19-20.

${ }^{59}$ Housley 2013, pp. 73-83.

${ }^{60} \mathrm{Cf}$. apéndice, párrafo 23 .
} 
de esta forma, consolidaba las dos caras de su poder, como jefe religioso que luchaba por la salvaguardia de la fe y como príncipe temporal que asumía el liderazgo político y militar. No en vano, se ha afirmado que la lucha contra el Turco y la construcción del poder papal fueron dos procesos inseparables en la segunda mitad del Cuatrocientos ${ }^{61}$.

\section{3. ¿EN UN MANUSCRITO LITÚRGICO? ACERCA DEL CÓDICE 56-23}

Además de su datación y del análisis de su contenido en relación con otros testimonios de la literatura de cruzada, el esclarecimiento de las circunstancias en que se produjo y utilizó nuestro texto exige también conocer el origen y la trayectoria del continente que lo ha conservado hasta nuestros días, el manuscrito 56-23 de la Biblioteca Capitular de Toledo, para comprender cuándo, dónde y por qué se incorporó a sus folios finales.

Como señalamos al comienzo, hasta la fecha este códice nunca había sido objeto de un estudio pormenorizado. Sin embargo, su texto contiene numerosos indicios que señalan indudablemente hacia un origen en los primeros años del siglo XV en el Languedoc, muy posiblemente en Aviñón o, cuando menos, en estrecha vinculación con el ambiente de la Curia papal durante los últimos tiempos de su estancia en la ciudad del Ródano. En tal dirección apuntan una serie de textos intercalados entre los ordines habituales de la familia de Guillermo Durando a la que pertenece ${ }^{62}$ : una cláusula de excomunión contra aquellos que atentaran contra la jurisdicción del obispo de Maguelone en la que también se alude a los condados de Melgueil y Montferrand, que en época medieval formaban parte del dominio jurisdiccional del obispo de Maguelone $^{63}$, y varios fragmentos del Ordo missae episcopalis, elaborado en Aviñón por el cardenal Giacomo Stefaneschi (1295-1343) ${ }^{64}$, así como una gran cantidad de santos franceses especialmente venerados en el Mediodía, men-

\footnotetext{
${ }^{61}$ Weber 2013a, pp. 13-14. Sobre el esencial componente bélico, tanto ideológico como real, del papado y la Iglesia romana en el siglo XV, véase el reciente trabajo de Chambers 2006.

${ }^{62} \mathrm{El}$ análisis pormenorizado de este manuscrito, enormemente complejo, trasciende los objetivos de este artículo. Por eso, me limito a presentar los principales indicios para su datación, con la intención de dedicarle una publicación futura de carácter monográfico.

63 "Item omnes illos qui invadunt iurisdictionem domini Magolonensi episcopi vel comitatus Melgorii vel Montisferrandi vel virum eiusdem comittatus sive ecclesie Magalense", f. 189v.

${ }^{64}$ La edición de este Ordo, llamado Ordo XIV por J. Mabillon en su Museum Italicum, puede consultarse en Migne 1862, cols. 1121-1274. Nuestro manuscrito contiene, en concreto, los siguientes textos: De communione eorum qui ordinantur (Ordo XIV, c. 56) (ff. 153v-154r); De communione episcoporum qui consecrantur et abbatis qui benedicitur (Ordo XIV, c. 57) (ff. 154r-154v); De missis defunctorum (Ordo XIV, c. 59) (ff. 154v-155r); y De missis que celebrantur coram papa (Ordo XIV, c. 60) (ff. 155r-156r).
} 
cionados en las letanías y bendiciones ${ }^{65}$. A ello hay que añadir la presencia de una fórmula de la benedictio arrarum tomada del Liber Ordinum hispánico ${ }^{66}$ y la alusión a dos santas características de la Península Ibérica, santa Eulalia y santa Tecla (f. 195v), rasgos ambos frecuentes en los libros litúrgicos languedocianos del tardomedioevo como consecuencia del estrecho contacto con el territorio castellano a través de la antigua Marca Hispánica ${ }^{67}$. Finalmente, en los ff. 115r-116r incluye el ordo De benedictione fetus in utero matris, que, según M. Andrieu, es característico de una serie de pontificales que bien fueron realizados en el Mediodía, bien se copiaron a partir de modelos de esa procedencia, lo que, en definitiva, sugeriría que esta bendición únicamente circuló -al menos en un principio- en Provenza y Languedoc ${ }^{68}$.

En paralelo, como argumentamos en nuestro artículo, su decoración presenta claros elementos de filiación holandesa, que caracterizaron a la producción miniada del entorno de la Corte papal en sus últimos años de estancia en Aviñón y en su regreso a Roma, pasando por Basilea durante la celebración del importante Concilio (1431-1438) ${ }^{69}$.

Perteneciendo a algún miembro de la Curia, es más que probable que el manuscrito fuera trasladado a Roma cuando la Corte papal regresó a la ciudad de san Pedro en tiempos de Martín V (1417-1431) o poco después y que allí se integrara o se empleara en la confección de un grupo peculiar de pontificales, franco-romanos y datables entre los años treinta y cincuenta, que M. Andrieu estudió bajo el apelativo de forme remaniée y con los que el ejemplar 56-23 presenta un estrechísimo paralelo ${ }^{70}$. Resulta igualmente verosímil suponer que, hacia esos mismos años y hallándose en Roma, se añadieran a nuestro manuscrito los textos de los ff. 205r-225v, esto es, la Descriptio basilicae Vaticanae, hasta la fecha identificada en dos códices producidos en ámbito romano ${ }^{71}$, y las Indulgentie ecclesiarum urbis Rome, que, como se señaló anteriormente, circularon con intensidad en esta ciudad desde la celebración del primer jubileo de 1300.

\footnotetext{
${ }^{65}$ San Marcial y san Gil (f. 12v), san Ginés (f. 185r), san Valeriano, san Remigio y san Rufo (f. 195r) o santa Blandina (f. 195v), entre otros.

66 "Benediccio arrarum. Benedic, Domine, arras istas quas hodie tradet famulus tuus (...) Deus Abraham, Deus Ysaac et Deus Iacobe ipse sit vobiscum et ipse vos coniugat impleatque benediccione sua in vobis. Amen”, ff. 200v-201v; véase Férotin 1904, col. 435.

${ }^{67}$ Martimort 1995.

${ }^{68}$ Andrieu 1940, pp. 678-680.

${ }^{69} \mathrm{Cf}$. nota 62 .

${ }^{70} \mathrm{Se}$ trata de los manuscritos de Metz, Bibliothèque municipale, 47, lamentablemente destruido en un incendio en 1944, París, Bibliothèque Nationale de France, lat. 734 y Ciudad del Vaticano, Biblioteca Apostolica Vaticana, Vat. lat. 4744; Andrieu 1940, pp. 298-300.

${ }^{71}$ Ciudad del Vaticano, Biblioteca Apostolica Vaticana, Vat. lat. 6757 y Vat. lat. 3627, ambos confeccionados en Roma, el primero, a principios del siglo XIII y el segundo, a finales del XV, Valentini, Zucchetti 1940-1953, vol. III, pp. 376-378.
} 
Esta trayectoria permitiría explicar que, apenas unos años después de estas adiciones y estando el códice en Roma, se incorporase el informe de cruzada que ahora nos ocupa, utilizando para ello los folios finales del último cuaderno que habían quedado en blanco. Tal contexto espacio-temporal de origen es, de hecho, plenamente coherente con la similitud de su escritura con la del ejemplar Vat. lat. 15178 de la Biblioteca Apostolica Vaticana, que, como vimos en el primer apartado, fue realizado en Roma entre 1457 y 1463.

Con posterioridad, el manuscrito aún sufrió nuevas modificaciones ${ }^{72}$, pero permaneció en el entorno de la Curia papal. Así parece deducirse, al menos, de que fuera en Roma donde, a finales del XVIII, lo adquirió el cardenal Francesco Saverio de Zelada, bibliófilo incansable, cardenal-bibliotecario de la Santa Romana Iglesia (1779-1801) y responsable de su traslado a la librería de la catedral toledana, donde todavía se conserva ${ }^{73}$.

\section{UN INFORME PARA LA CRUZADA DE PÍO II}

La presencia de nuestro texto en un manuscrito litúrgico estrechamente vinculado con la Curia, primero aviñonesa y después romana, unida a su datación en 1458, al ideario de cruzada subyacente y al profundo conocimiento de la realidad turca que manifiesta, según se ha analizado en los apartados precedentes, conduce a la conclusión de que este nuevo testimonio fue compuesto y utilizado en el ambiente de la Corte pontificia; más concretamente, nos permite relacionarlo con el entorno de Eneas Silvio Piccolomini, Pío II, puesto que el ideario político-militar examinado concuerda plenamente con el espíritu de cruzada que constituyó el eje vertebral de su papado.

En efecto, y tal y como han puesto de relieve numerosos autores ${ }^{74}$, antes de ascender a la cátedra de san Pedro este destacado humanista ya había manifestado la necesidad de unidad entre los países europeos para hacer frente al auge del poder otomano ${ }^{75}$. Y esta percepción no hizo sino acentuarse tras la caída de Constantinopla. No sorprende, entonces, que, en octubre de 1458, apenas un mes después de haber recibido la tiara pontificia, Pío II pronunciara

\footnotetext{
${ }^{72}$ Así lo demuestran los restos de escritura contenidos en el f. $228 \mathrm{v}$, lamentablemente recortado casi en su totalidad, pero en el que todavía son legibles dos fechas -1462 y 1464 - y una referencia a la consagración de una capilla de Santa María, de ubicación desconocida.

${ }^{73}$ Sobre la trayectoria de los manuscritos de Zelada hasta la Biblioteca Capitular de Toledo, véase López-Mayán 2015.

${ }^{74}$ La literatura sobre Pío II y la cruzada contra el Turco es amplísima; entre las aportaciones más recientes, véanse Bisaha 2004, pp. 39-52; Baldi 2006, 2008; Corradini 2006; Ginzo 2011; Weber 2014, pp. 240-241.

${ }^{75}$ Fernández 2010, pp. 22-23.
} 
ante el colegio cardenalicio un largo discurso en el que explicó cuáles habían sido los terribles daños provocados por el Turco y de qué manera debía defenderse la cristiandad. A su entender, el mejor medio posible era organizar una gran cruzada, para lo cual convocó varios encuentros preparatorios en Roma y promulgó la famosa bula Vocavit nos Pius, en la que instaba a las potencias cristianas a unir su capacidad económica y militar para hacer la guerra santa contra el Imperio otomano. La idea del pontífice era celebrar una gran reunión con los diversos líderes occidentales en Mantua a comienzos del verano de 1459 , pero la falta de interés hacia el proyecto provocó su absoluto fracaso. Con posterioridad, y tras intentar un acercamiento a Mehmed II por vía diplomática $^{76}$, Pío II retomó el plan de la cruzada y en 1463 volvió a convocar a las potencias occidentales a una campaña que él mismo decidió encabezar. Como es bien sabido, el 18 de mayo de 1464 embarcó en Puente Milvio y dos meses después llegó a Ancona, pero allí contrajo la peste y murió, lo que puso fin al último intento sistemático del papado de combatir la amenaza otomana.

En lo que ahora más nos interesa, el pontífice legitimó ambos proyectos de cruzada a través de un ideario que coincide plenamente con el que subyace en nuestro texto. Con ellos Pío II actuaba en coherencia con la motivación plenomedieval de la guerra religiosa contra el infiel, pero, sobre todo, perseguía responder al imperativo humanista de luchar contra la barbarie, identificada con el mundo otomano, y en defensa de la civilización, considerada consustancial a la cristiandad ${ }^{77}$. Además, el despliegue de tales iniciativas debía servirle para reafirmar el papel del papado y su autoridad sobre el conjunto de la Europa cristiana a través del liderazgo económico y militar que, como hemos visto, se refleja en el texto del manuscrito 56-23. Por último, conviene no olvidar que, en razón de esta preocupación y de su convencimiento de que para triunfar en la lucha contra el Turco era necesario familiarizarse con su geografía y su historia, Pío II fue un profundo conocedor del Imperio de Mehmed y, más allá, de toda Asia Menor y de los Balcanes ${ }^{78}$. Y esta estrecha familiarización con la realidad oriental está también bien atestiguada en nuestro documento.

Hacia 1458 no solo Pío II esgrimía este ideario acerca de la cruzada contra el Otomano y de la afirmación del poder papal en Occidente; también el Colegio cardenalicio romano lo defendía entonces con gran beligerancia.

\footnotetext{
${ }^{76}$ En este contexto, redactó una famosa carta dirigida a Mehmed II, que, aunque nunca se llegó a enviar, se convirtió en un ejemplo paradigmático de la retórica política pontificia del Renacimiento, Soykut 2011, p. 228. Entre los estudios más recientes sobre este texto, véanse Bisaha 2002; Fernández 2004; Weber 2008.

${ }^{77}$ Ginzo 2011, p. 91. Véase también el clásico trabajo de Matanic 1964.

${ }^{78}$ Así lo manifestó en su obra Descriptio Asiae, escrita en 1461 como segundo volumen de un proyecto mayor, una Historia rerum ubique gestarum locorumque descriptio, que no pudo completar, Fernández 2010, pp. 26-27.
} 
No en vano, desde comienzos del Cuatrocientos esta institución representaba el gran cuartel general de la cruzada tardía y tal función se había visto acentuada desde tiempos de Eugenio IV (1431-1447) con la incorporación de dos cardenales de origen oriental, especialmente activos en la diplomacia papal y bien conocedores de la realidad otomana: Isidoro de Kiev y Giovanni Bessarione. Ambos terminaron siendo, de hecho, decanos del Colegio en coincidencia parcial con el mandato de Pío II $^{79}$, se implicaron personalmente en la lucha contra el infiel y estuvieron directamente relacionados con la elaboración de múltiples proyectos de cruzada ${ }^{80}$. El propio Bessarione escribió unas famosas Orationes ad principes christianos contra turcos en las que, en la misma línea argumental visible en nuestro texto, señaló la importancia de la paz y la unidad entre las potencias europeas como condiciones necesarias para hacer frente a la inminente amenaza turca ${ }^{81}$.

¿Pudo haber sido el escrito que nos ocupa concebido, elaborado y utilizado en el seno de este Colegio cardenalicio durante la preparación de la cruzada proyectada por Pío II en el otoño de 1458? En su obra De expeditione Pii Papae II adversus Turcos, compuesta hacia 1460-1464, poco después de la reunión de Mantua del 1 de junio de 1459, el humanista Leodrisio Crivelli ofrece un dato interesante en este sentido. Según él, antes del encuentro mantuano, Pío II convocó y presidió tres reuniones preparatorias en la Ciudad del Vaticano en las que el Colegio cardenalicio y el propio Bessarione tuvieron un protagonismo esencial: el 10 de octubre, el 13 de octubre -en la que leyó la bula Vocavit vos - y el 12 de diciembre de 1458. En esta última, añade, los asistentes -embajadores de Nápoles, Venecia, Milán, Florencia y Módena- expusieron los recursos militares y económicos que sus estados podían aportar ${ }^{82}$. Teniendo en cuenta las circunstancias de origen y la naturaleza de nuestro texto, resulta altamente verosímil que fuera producido a modo de apuntes informativos que circularon en el Colegio cardenalicio en una de esas reuniones previas a Mantua. Máxime si tenemos en cuenta que se crearon de ese mismo modo, como material de trabajo de la comisión de cardenales, otros testimonios de la literatura de cruzada que han sobrevivido hasta nuestros días, como el ya citado Strategicon adversum Turcos de Lampo Birago ${ }^{83}$ o dos memoriales financieros para el armamento de los barcos que debían operar con la flota veneciana para ayudar en la cruzada de Pío II y que fueron presentados oficialmente en la reunión de Mantua ${ }^{84}$.

\footnotetext{
${ }^{79}$ Isidoro de Kiev lo fue entre 1461 y 1463 y el cardenal Bessarione, entre 1463 y 1472.

${ }^{80}$ Sobre esta cuestión véase Muresan 2014.

${ }^{81}$ Manselli 1973.

${ }^{82}$ Zimolo 1950, pp. 80-100.

${ }^{83}$ Damian 2012.

${ }^{84}$ Carusi 1915.
} 
De ello sería posible extraer otra conclusión: si nos hallamos ante un informe provisional o borrador confeccionado y usado en el ámbito cardenalicio y considerando, como señalamos antes, que posiblemente se escribió directamente sobre los folios finales del manuscrito 56-23, entonces tendríamos que considerar que el propio códice que lo contiene pertenecía a alguno de los asistentes a tales reuniones, posiblemente un cardenal o un miembro de la Curia. Un último argumento corrobora la vinculación de este manuscrito con dicho ambiente: poco tiempo después de haber sido escrito nuestro texto, la misma mano responsable añadió dos anotaciones marginales junto a las alusiones al papado en las listas de gastos e ingresos en las que se indica que los estados pontificios hodie etiam hunt alumen (f. $225 \mathrm{v}$ ) e item propter alumen $(\text { f. } 226 \mathrm{v})^{85}$. Obviamente, se trata de sendas alusiones a las minas de alumbre de Tolfa, precisamente descubiertas en 1462, en tiempos de Pío II, y celebradas con gran regocijo por la Curia, cuyo abastecimiento de este producto, imprescindible en la producción textil, dependía hasta entonces del comercio con Egipto, Siria y Anatolia y se había visto muy limitado por el avance otomano ${ }^{86}$. Teniendo en cuenta que en 1463 Pío II decidió destinar los beneficios económicos derivados de la explotación de estas minas a la financiación de la cruzada -aunque en términos efectivos no fue así hasta tiempos de Pablo II- ${ }^{87}$, cabría pensar que en ese año el manuscrito 56-23 seguía perteneciendo al mismo propietario y que éste continuaba formando parte del círculo más cercano al pontífice romano.

La falta de documentación complementaria que corrobore esta conclusión nos obliga a permanecer en el ámbito de lo hipotético. No obstante, a partir de la argumentación y de los paralelos expuestos en las páginas precedentes consideramos que es posible afirmar que nos hallamos ante un informe técnico, de carácter provisional, confeccionado en el seno del Colegio cardenalicio romano o en estrechísima relación con él y utilizado en la preparación del proyecto de cruzada que Pío II emprendió en 1458. Desde este punto de vista, se trata de un documento no solo inédito, sino también de gran valor histórico, especialmente si tenemos en cuenta la notable carencia de fuentes precisas y concisas que afecta a nuestro conocimiento sobre la estrategia y el proyecto de dicho pontífice ${ }^{88}$.

Como es bien sabido, tal ideario chocó frontalmente con la realidad europea de la segunda mitad del siglo XV. La evolución de los acontecimien-

\footnotetext{
${ }^{85} C f$. apéndice, párrafos 6 y 14 .

${ }^{86}$ Delumeau 1963, pp. 20-21. Más recientemente, véanse Jacoby 2005; Weber 2013b.

${ }^{87}$ Aunque tal medida no fue realmente efectiva hasta tiempos de Pablo II, Weber 2013a, pp. 315-324.

${ }^{88}$ Ibidem, p. 240.
} 
tos en los años que siguieron a 1458 confirmó que ni siquiera la acuciante amenaza del temido Imperio otomano podía modificar la tendencia de los estados europeos hacia la consolidación de sus propias fronteras y de sus aparatos gubernamentales. Frente a ello, las diversas iniciativas implementadas por Pío II y su entorno, entre las que se debe incluir el texto descubierto en el manuscrito 56-23, no fueron más que un desesperado y fracasado intento de aferrarse a una concepción universalista del papado y de Europa que estaba en franco retroceso en los albores de la modernidad.

\section{BIBLIOGRAFÍA CITADA}

Albanese, Gabriella (2008), La storiografia umanistica e l'avanzata turca: dalla caduta di Costantinopoli alla conquista di Otranto, en Houben, Hubert (ed.), La conquista turca di Otranto (1480) tra storia e mito, Galatina, Congedo, vol. I, pp. 319-352.

Andrieu, Michel (1940), Le Pontifical romain au Moyen Âge, vol. III: Le Pontifical de Guillaume Durand, Ciudad del Vaticano, Biblioteca Apostolica Vaticana.

Babinger, Franz (1978), Mehmed the Conqueror and his time, Princeton, Princeton University Press.

Baldi, Barbara (2006), Pio II e le trasformazioni dell'Europa cristiana (14571464), Milán, Edizioni Unicopli.

Baldi, Barbara (2008), Il problema turco dalla caduta di Costantinopoli (1453) alla morte di Pio II (1464), en Houben, Hubert (ed.), La conquista turca di Otranto (1480) tra storia e mito, Galatina, Congedo, vol. I, pp. 55-76.

Bisaha, Nancy (2002), Pope Pius II's letter to Sultan Mehmed II: a reexamination, "Crusades" 1, pp. 183-188.

Bisaha, Nancy (2004), Pope Pius II and the Crusade, en Housley, Norman (ed.), Crusading in the Fifteenth Century. Message and Impact, Basingstoke, Palgrave, pp. 39-52.

Caldelli, Elisabetta (2006), Copisti a Roma nel Quattrocento, Roma, Viella.

Carusi, Enrico (1915), Preventivi di spese per la spedizione contro il Turco al tempo di Pio II, “Archivio Muratoriano" 16, pp. 273-279.

Corradini, Sandro (2006), Preparazione della crociata contro il turco e tramonto di un sogno di Pio II, en Di Paola, Roberto; Antoniutti, Arianna (eds.), Enea Silvio Piccolomini. Arte, storia e cultura nell'Europa di Pio II, Roma, Libreria Editrice Vaticana, pp. 263-278.

Chambers, David (2006), Popes, cardinals and war. The military church in Renaissance and Early Modern Europe, Nueva York, I. B. Tauris. 
Damian, Iulian M. (2012), From the Italic League to the Italic Crusade: Crusading under Renaissance Popes Nicholas V and Pius II, en Damian, Iulian Mihai; Pop, Ioan-Aurel; Popovic, Mihailo; Simon, Alexandru (eds.), Italy and Europe's Eastern Border (1204-1669), Frankfurt Nueva York, Peter Lang, pp. 79-94 (Series Eastern and Central European Studies; 1$)$.

Delumeau, Jean (1963), L'Alun de Rome (XVe-XIX siècle), París, École Pratique des Hautes Études.

Derolez, Albert (2006), The palaeography of Gothic Manuscript Books from the twelfth to the early sixteenth century, Cambridge, Cambridge University Press.

Ellissen, Adolf S. (1857), Analekten der mittel- und neugriechischen Literatur, vol. V, Leipzig, O. Wigand.

Fernández Sanz, Domingo (ed.) (2004), Eneas Silvio Piccolomini. Epístola a Mehmet II, Madrid, CSIC.

Fernández Sanz, Domingo (ed.) (2010), Eneas Silvio Piccolomini. Descripción de Asia, Madrid, CSIC.

Férotin, Marius (1904), Le Liber Ordinum en usage dans l'Église wisigothique et mozarabe d'Espagne du cinquième au onzième siècle, París, Firmin-Didot.

Fine, John V. A. (1987), The late medieval Balkans: a critical survey from the twelfth century to the Ottoman conquest, Ann Arbor, The University of Michigan Press.

Fleet, Kate (2000), Turks, Italians and Intelligence in the Fourteenth and Fifteenth centuries, en The Balance of Truth. Essays in Honour of Professor Geoffrey Lewis, Estambul, Gorgias Press - The Isis Press, pp. 99-112.

Fleet, Kate (2009), The Turkish economy, 1071-1453, en Fleet, Kate (ed.), The Cambridge History of Turkey. vol. I: Byzantium to Turkey 10711453, Cambridge, Cambridge University Press, pp. 227-265.

Fodor, Pál (2008), The Ottoman empire, Byzantium and Western Christianity: the implications of the siege of Belgrade, 1456, "Acta Orientalia Academiae Scientiarum Hungaricae" 61, pp. 43-52.

Freely, John (2009), The Grand Turk: Sultan Mehmet II, Conqueror of Constantinople, Master of an Empire and Lord of Two Seas, Londres, I. B. Tauris.

Ginzo Fernández, Arsenio (2011), Eneas Silvio Piccolomini (Pío II) y su concepción de Europa, "Anales del Seminario de Historia de la Filosofía” 28, pp. 71-100.

Hankins, James (1995), Renaissance Crusaders: Humanist Crusade Literature in the Age of Mehmed II, "Dumbarton Oaks Papers" 49, pp. 111-207. 
Housley, Norman (1992), The Later Crusades, 1274-1580: From Lyons to Alcazar, Oxford, Oxford University Press.

Housley, Norman (2013), Crusading and the Ottoman Threat (1453-1505), Oxford, Oxford University Press.

Inalcik, Halil (1960), Mehmed the Conqueror (1432-1481) and his time, "Speculum" 35 , pp. 408-427.

Inalcik, Halil (1993), The Middle East and the Balkans under the Ottoman Empire, Bloomington, Indiana University.

Inalcik, Halil; Quataert, Donald (eds.) (1994), An economic and social history of the Ottoman empire (1300-1914), Cambridge, Cambridge University Press.

Iorga, Nicolas (1899-1916), Notes et extraits pour servir à l'histoire des croisades au XV siècle, 6 vols, París, E. Leroux - Bucarest, Académie roumaine.

Jacoby, David (2005), Production et commerce de l'alun oriental en Méditerranée, $X I^{e}-X V^{e}$ siècles, en Borgard, Philippe; Brun, Jean-Pierre; Picon, Maurice (dirs.), L'alun de la Méditerranée, Nápoles, Publications du Centre Jean Bérard, pp. 219-267.

Janini, José; Gonzálvez, Ramón (1977), Catálogo de los manuscritos litúrgicos de la Catedral de Toledo, Toledo, Diputación Provincial de Toledo.

Karpov, Sergej (1986), L'impero di Trebisonda, Venezia, Genova e Roma (1204-1461): rapporti politici, diplomatici e commerciali, Roma, Il Veltro.

Kay, Richard (2007), Pontificalia. A repertory of latin manuscript pontificals and benedictionals, Lawrence, University of Kansas.

Kiel, Machiel (2009), The incorporation of the Balkans into the Ottoman Empire, 1353-1453, en Fleet, Kate (ed.), The Cambridge History of Turkey, vol. I: Byzantium to Turkey 1071-1453, Cambridge, Cambridge University Press, pp. 138-191.

López-Mayán, Mercedes (2012), Liturgia y manuscritos en la Castilla medieval: algunos problemas metodológicos en el estudio de los pontificales, en Estudiar el pasado: aspectos metodológicos de la investigación en Ciencias de la Antigüedad y de la Edad Media, Oxford, Archaeopress, pp. 418-425.

López-Mayán, Mercedes (2015), Entre la liturgia y el coleccionismo: la circulación de pontificales italianos en la España bajomedieval y moderna, "Nuovi Annali della Scuola Speciale per Archivisti e Bibliotecari" 29, pp. 5-24.

López-Mayán, Mercedes (en prensa), De Aviñón a Roma: nuevas reflexiones sobre las transferencias litúrgicas y artísticas al final del Cisma, "Medievalia. Revista d'Estudis Medievals". 
Manselli, Raoul (1973), Il cardinale Bessarione contro il pericolo turco e l'Italia, "Miscellanea francescana" 73, pp. 314-326.

Manz, Beatrice F. (2005), Tamerlane: his rise and rule, Londres, Folio Society.

Martimort, Aimé-Georges (1995), Sources, histoire et originalité de la liturgia catalano-languedocienne, en Liturgie et musique (IXe-XIVe siècle), Toulouse, Privat (Cahiers de Fanjeaux; 17).

Matanic, Atanazije G. (1964), L'idea et l'attività per la crociata anti-turca del papa Pio II (1458-1464), "Studi francescani" 61, pp. 382-394.

Meserve, Margaret (2004), Italian Humanists and the Problem of the Crusade, en Housley, Norman (ed.), Crusading in the Fifteenth Century. Message and Impact, Basingstoke, Palgrave, pp. 13-38.

Migne, Jean-Paul (ed.) (1862), Patrologiae cursus completus. Series latina, vol. 78, París, Petit-Montrouge.

Muresan, Dan Ioan (2014), La croisade en projets. Plans présentés au Grand Quartier Général de la Croisade, le Collège des cardinaux, en Paviot, Jaques (dir.), Les projets de croisade. Géostratégie et diplomatie européenne du XIV au XVII siècle, Toulouse, Presses universitaires du Mirail, pp. 247-286.

Murphey, Rhoads (2010), Ottoman military organisation in South-Eastern Europe, c. 1420-1720, en Tallett, Frank; Trim, D.J.B. (eds.), European warfare, 1350-1750, Cambridge, Cambridge University Press, pp. 135-158.

Nicolle, David; Turnbull, Stephen; Haldon, John (eds.) (2007), The Fall of Constantinople: the Ottoman conquest of Byzantium, Oxford, Osprey Publishing.

Orlando, Ermanno (2009), Tra Venezia e Impero ottomano: paci e confine nei Balcani occidentali (secc. XV-XVI), en Ortalli, Gherardo; Schmitt, Oliver Jens (eds.), Balcani occidentali, Adriatico e Venezia fra XIII e XVIII secolo, Viena, Verlag der Österreichischen Akademie der Wissenschaften, pp. 103-178.

Panaite, Viorel (2000), The Ottoman law of war and peace: the Ottoman Empire and tribute payers, Nueva York, East European Monographs.

Paviot, Jacques (ed.) (2008), Projets de croisade (v. 1290 - v. 1330), París, Académie des inscriptions et belles-letrres.

Paviot, Jacques (ed.) (2014a), Les projets de croisade. Géostratégie et diplomatie européenne du XIV au XVII siècle, Toulouse, Presses universitaires du Mirail.

Paviot, Jacques (2014b), L'idée de croisade à la fin du Moyen Âge, en Paviot, Jacques (ed.), Les projets de croisade. Géostratégie et diplomatie européenne du XIV au XVII siècle, Toulouse, Presses universitaires du Mirail, pp. 17-29. 
Pertusi, Agostino (1970), I primi studi in Occidente sull'origine e la potenza dei Turchi, "Studi veneziani” 12, pp. 465-552.

Pertusi, Agostino (1974a), La lettera di Filippo da Rimini, cancelliere di Corfù, a Francesco Barbaro e i primi documenti occidentali sulla caduta di Costantinopoli (1453), en Mnemosynon Sofias Antoniade, Venecia, dell'Istituto Ellenico di Studi bizantini e postbizantini di Venezia, pp. 120-157.

Pertusi, Agostino (1974b), Le notizie sulla organizzazione amministrativa e militare dei Turchi nello Strategicon adversum Turcos di Lampo Birago (c. 1453-1455), en Studi sul Medioevo cristiano offerti a Raffaello Morghen per il $90^{\circ}$ anniversario dell'Istituto Storico Italiano (1883-1973), Roma, Istituto Storico Italiano per il Medio Evo, vol. II, pp. 669-700.

Pertusi, Agostino (1977), Le epistole storiche di Lauro Quirini sulla caduta di Costantinopoli e la potenza dei turchi, en Lauro Quirini umanista, Florencia, Olschki, pp. 163-259.

Pitcher, Donald E. (1972), An historical geography of the Ottoman empire from earliest times to the end of the sixteenth century, Leiden, Brill.

Puig de la Bellacasa, Ramón; Servantie, Alain (eds.) (2005), L'Empire ottoman dans l'Europe de la Renaissance: idées et imaginaires d'intellectuels, de diplomates et de l'opinion publique dans les anciens Pays-Bas et le monde hispanique aux $X V^{e}, X V I^{e}$ et début du XVII ${ }^{e}$ siècles, Lovaina, Leuven University Press.

Sabbatini, Ilaria (2010), Io ci vidi molti saracini. La rappresentazione del mondo musulmano del Vicino Oriente nell'odeporica di pellegrinaggio tardo medievale, "Giornale di Storia" 4, http://www.giornaledistoria.net/index.php?Articoli=557D0301220A7403210005767773 [consulta: 13/06/2014].

Setton, Kenneth M. (1978), The Papacy and the Levant, vol. II: The Fifteenth century, Filadelfia, The American Philosophical Society.

Shaw, Stanford J. (1976), History of the Ottoman Empire and modern Turkey, vol. I: Empire of the Gazis: the rise and decline of the Ottoman empire, 1280-1808, Cambridge, Cambridge University Press.

Shawcross, Teresa M. (2009), The Chronicle of Morea: historiography in crusader Greece, Oxford, Oxford University Press.

Soykut, Mustafa (2001), Image of the Turk. A history of the Other in early modern Europe (1453-1683), Berlín, Klaus-Schwarz Verlag.

Soykut, Mustafa (2011), Note sui rapporti tra Italia, Islam e Impero Ottomano (secoli XV-XVIII), "Archivio Storico Italiano" 169/2, pp. 221-240. 
Valentini, Roberto; Zucchetti, Giuseppe (1940-1953), Codice topografico della Città di Roma, 4 vols., Roma, Istituto Storico Italiano per il Medio Evo.

Weber, Benjamin (2008), Conversion, croisade et oecuménisme à la fin du Moye-âge: encore sur la lettre de Pie II à Mehmed II, "Crusades" 7, pp. 181-197.

Weber, Benjamin (2013a), Lutter contre les Turcs. Les formes nouvelles de la croisade pontificale au XV siècle, Roma, École Française de Rome.

Weber, Benjamin (2013b), L'alun de la croisade? Étapes et difficulté de la mise en place d'un monopole pontifical sur l'alun de Tolfa (1461-1471), "Cahiers des recherches médiévales et humanistes" 25, pp. 597-619.

Weber, Benjamin (2014), Y a-t-il eu des projets de croisade pontificaux au $X V^{e}$ siècle?, en Les projets de croisade. Géostratégie et diplomatie européenne du XIV au XVII siècle, Toulouse, Presses universitaires du Mirail, pp. 231-246.

Zimolo, Giulio C. (ed.) (1950), Leodrisii Cribelli, De expeditione Pii Papae II adversus Turcos, Bolonia, N. Zanichell.

\section{APÉNDICE DOCUMENTAL}

Toledo, Biblioteca Capitular, ms. 56-23, ff. 225v-227v $\mathrm{v}^{89}$

(f. 225v)

[1] Redditus potentiarum nobis notarum et eorum potentiae in bellis. / $<$ Concesso quam christiani inito bello profligarent Turchum mala infinita fidelibus acciderent>.

[2] Soldatus cum vectigalibus laicorum et clericorum habet proaentur / iiii millionu $m$ auri / in patria potest habere equitum $\mathrm{c}$ milia, extra patriam propter dupplices sumptus L milia. 50 milia. / Caramannus cum vectigalibus ut supra domi potest nutrire pro exercitu equitum $1 \mathrm{x}$ milia, foris 30 milia. / Carailef cum vectigalibus ut supra domi equitum xx milia, foris 10 milia. / Caraisanus cum vectigalibus domi equitum xx, foris 10 milia. / Jamsa cum vectigalibus domi equitum cc, foris 100 milia. / Tamborlanus cum vectigalibus domi equitum unum millionem, foris 500 milia. / Reges Tunes, Granate et ibide $m$ alii barbari principes in Africa aedificarent / sane multas triremes,

\footnotetext{
${ }^{89}$ La transcripción se ha estructurado en párrafos, cuyo número se utiliza a lo largo del estudio previo para remitir a su contenido, pero refleja la disposición original del texto al indicarse mediante una barra inclinada (/) cada cambio de línea. Para facilitar su lectura, se han desarrollado sus numerosas abreviaturas, señalándose en cursiva las letras añadidas. Asimismo, se expresa entre ángulos $(\diamond)$ el texto añadido al margen o entre renglones en el original. Finalmente, el paréntesis con puntos suspensivos (...) indica la presencia de una palabra que resulta ilegible.
} 
biremesque et nauigia horum vires et domi equitum c milium, 50 milia foris. / Summa Mahometanorum foris equitum 750 milium. / Turchus nutrit equitum domi forisque milia, 400 milia. / Summa omnium simul est 1150 milium. /

[3] Anno 1010 uniti omnes infideles Hungariam et Graeciam occuparunt, Romam quoque uenerunt nisi / Deus prouidisset in eo scandalo actum erat de christianis. / Si anno 1400 christiani debellassent Turchum cum Tamborlano inisset concordiam in eum fidem / christianorum propter victoria de christianis elatus est contra Tamborlanum quid bene fidelibus cessit. /

[4] Christiani principes. / Rex Franciae habuit anno 1414 redditus quinque millionum propter bellum annorum xl, redactus est ad 1000 milia. / Rex Angliae eodem tempore habuit ii milliones sed (...) <intestinis> redacta est insula ad redditus ordinarios 700 milia. / Rex Hispaniae anno 1410 habuit ii milliones, redactus est propter bello ad annue redditus ordinarios $800 \mathrm{milia}$. / Rex Portusgalliae habebat eodem tempore annue redditum ordinarios cc milia ducatos, redactus est ad annue redditus 140 milia. /

[5] Dux Britaniae habebat ordinarios redditus annue cc milia propter assidua bella, redactus est ad ducatos 140 milia. / Dux Burgundiae habebat ordinarios redditus annue iii milliones propter eadem casum, redactus est ad ducatos 900 milia. / Dux Sabaudiae propter propriam liberam habebat ordinarios annue redditus ducatos 150 milia. / Marchio Montisferrati habebat eadem ratione ordinarios annue redditus ducatos 100 milia. / Dux Mediolani anno 1423 habebat annue redditus ordinarios i millionem et ducatos dccc milia propter bella, redactus est ad ducatos 500 milia. / Dominium Venetorum eodem tempore habebat annue i millionem et ducatos ccc milia, eade $m$ ratione redactum est ad annue, redditus ordinarios ducatos $500 \mathrm{mi}$ lia. / Marchio Mantuanus eodem tempore habebat annue ordinarios, annue redditus ducatos cl milia propter bella, est/ redactus ad ducatos 60 milia. / Dux Mutine eodem tempore habebat annue ducatos lxx milia, inter bella uero Italiae ipse paci / ficus manens excreuit ad annue redditus ordinarios ducatos 150 milia. / Bononienses eodem tempore habebant redditus annue ordinarios ducatos cl milia, propter inquietas agitationes / suas continentes et assiduas redacti sunt ad ducatos 50 milia. / Lucenses tunc quoque habebant annue redditus ordinarios ducatos cc milia, propter bella redacti sunt ad 60 milia. / Florentini etiam tunc habebant redditus annue ordinarios ducatos cccc milia, propter bella redacti sunt ad 200 milia. /

[6] < Hodie etiam hunt alumen $>$ Summus pontifex habebat prius multo plus, nunc habet redditus annue ordinarios usque ad ducatos 400 milia. / Genuenses solebant habere magnos ordinarios annue redditus, propter intestinas seditiones iux exigunt ducatos 180 milia. / Rex Aragonum olim multo plus, nunc de regno suo et Sicilia habet annue ordinarios redditus ducatos 800 milia. / Summa antedictorum potentarium est ducatos auri / milliones sex et octigenta triginta milia: 6830 milia. / Rex (...) habet de (...) de redittibus cccclxxx annue ducatos auri 480 milia. /

[7] Redditus Turchi ordinarii. / In Graecia habet focos i familias separatas ad unum millionem et de milia, ex quibus decc milia / sunt christianorum qui 
soluunt in tributo annuo a iii usque in $\mathrm{x}$ ducatos pro singulis focis. / Itaque si unus est inops ut tamen non possit soluere, diuitis solutio compensatur. Pro paupere / sunt ducati annue ii milliones et cccc milia. 2400 milia. / Ex decimis fructuum omnium terrae animaliumque magnorum et minutorum ac caseorum reliqui / foci Turchorum qui sunt in Graecia soluunt annue i millionem ducatos. 1000 milia. / Item foci ipsi Turchorum qui sunt decc milia soluunt dimidium ducatos singuli annue ducatos. 400 milia. / Vectigal mercimoniorum soluentum unum pro centenario reddit annue ducatos 100 milia. / Tributa moraeae Albaniae, Seruiae, Rhasiae, Bosnae comitis Stephani reddit annue ducatos 100 milia. / Ex sale qui consumitur singulis annis in Graecia redduntur annue ducatos 250 milia. / Ex passu Gallipolitano vectigal capitum i captiuorum qui ex christianis capiuntur annue / ex decima Turcho pertinenti, locata conductoribus redduntur singulis annis ducatos 150 milia. / Summa reddituum ordinarios annue in Graecia 4450 milia. /

[8] Redditus qui sunt in Turchia. / Habet focos ad ii milliones et d milia ex christianis qui ad predictam et omnem redditus annue ducatos 1500 milia. / Item ex Turchis unum millionem qui soluunt ducatos I pro foco redditus annue ducatos 750 milia. / Ex decimis frugum terrae animalium magnorum et minutorum caseorum et cottoni i bombacis ducatos 500 milia. / Ex sale qui consumitur in Turchia habet redditus annue ordinarios ducatos 150 milia. / Vectigal mercium intrantium exeuntiumque per Turchiam habet redditus annue ordinarios ducatos 100 milia. / Ex alumine rocae annue ducatos 30 milia. / Ex tributis a Charamanno Synope, Simiso et satrapis minorubis Turchiae redditus annue ordinarios ducatos 100 milia. / Summa ex Graecia et Turchia 7780 milia. /

[9] Impensae annuae quas amoratbei potere Turchi faciebat hae sunt. / Emebat pro annue: / A Venetis, Genuensibus, Florentinis inter pannos aureos et saericios et localia pro ducatos 150 milia. / Louestorum pannorum pecias milles emebat pro ducatos 16 milia. / Quadragenorum pannorum pecias mille pro ducatos 14 milia. / Pannorum de lx pecias quingentas pro ducatos 12 milia. / Pannorum de lxx in lxxx pecias quingentas pro ducatos 25 milia. / Françias sive fimbrias garbas usque ad pecias quingentas, ducatos 25 milia. / Franzias sive fimbrias finas i preciose factas ad pecias mille, ducatos 60 milia. / Pannorum scarlatorum pecias quingentas ex Paduanis, Vonensibus, Mantuanis, ducatos 35 milia. / Pannorum bastardorum apertorum pecias quingentas, ducatos 20 milia. / Pannorum bastardorum clausorum pecias mille, ducatos 25 milia. / Velorum sericeorum, lucentium, crisporum et planorum seu plumatorum, pro ducatos 25 milia. / Pannorum sericeorum feorum in Bursia, ducatos 100 milia. / Summa rerum omnium huiusmodi quas distribuebat suis curialibus ducatos 507 milia. /

[10] Turchus sing $u$ lis annis congregabat exercitum a tribus partibus equitum c milium quos per sex / menses foris tenebat, dabat pro stipendiis sing $u$ lis equitibus dietim aspros quattuor. / Ad rationem asprorum xxxii pro ducato, ascendebat dicta impensa cotidie ducatos 2000. / Pro mensibus sex ascendebat ad asprorum lxxii milliones cclii milia in summa ducatos 2250 milia. / Item omni anno in sagittis bombardisque pro tali expeditone ac aliis neces-/ sariis rebus expensarum ordinariarum in summa ducatos 1000 milia. /

(f. 226v) 
[11] In familia janicerorum suorum et copiarum pedestrium exercitu omni anno pro salario et expensis impe / dimentorum i necessariarum rerum ad usum belli et victus et equorum, ducatos 2000 milia. / In munitonibus annuis pro supplemento eorum que absumebantur, ducatos 500 milia. / In elemosinis annue, ducatos 100 milia. / Pro expensis trium suorum bassa ii capitaneorum quorum primus habet ducatos 50 milia, reliqui singuli 30 milia ducatos, 110 milia. / Summa impensae armorum ducatos 6 millionum ut 60 milia omnibus computans sunt ducatos 6567 milia. / Turchus ipse reponebat sing $u$ lis annis ultra omnem suam expensa $m$ ducatos i millionem cc xiii milia ducatos, 1213 milia. / Ego nullum cognosco ex principibus pernominatis cui aliquid supersit, inmo remanent in grauibus debitis omni anno. /

[12] Impensa lancearum c milium christianorum peritorum in re militari extra domum propriam ad minus omni mense debet essere / xx ducatorum pro lancea. Ascendit annue ad ducatorum xxiiii milliones. In expensa / uero sagittarum, lancearum, scloppetorum siue pyxidum, pulueris bombardae et siluerum neces / sariorum requirunt $u r$ annue xii milliones, quae in totum ascendit ad xxxvi milliones ducatos, 36 milliones. / Ubi reperietur tam grandis pecuniarum summa. / Volo sint c milia ualentium equinem, lancearorum et peritorum in re bellica c milia, equitum gallupporum / cum stambechinis i valistis ad hoc exercitatorum tandem equitum sacromannorum qui henant / pars arcus, pars autem scloppetos sive pyxides. Hi omnes sint equestres. /

[13] Sequitur suppuratio omnium potentiarum fidelium ordinanti approbata. / Rex Franciae cum suis omnibus redditibus et principum suorum tam laicorum propter ecclesia sticorum additis angariis omnium subditorum suorum nutrire potest equitum peritorum in armis annue domi milia 30, foris autem 15 milia. / Ante Anglicum bellum nutriebat $<$ domi $>$ equitu $m \mathrm{c}$ milia, bellum vexavit patriam et redditus minuit 15 milia. / Rex Angliae pari modo solvendo sing $u$ lis mensibus debita stipendia domi 30 milia, foris autem $15 \mathrm{mi}$ lia. / Ante anglicorum principum seditiones, quam hae potentiae sunt pares anno 1414, nutrisset domi/ equitum c milia, intestinae factiones insulam confecerunt. / Rex Scotiae quam dominus est magnae patriae et proprii sed inopis ut supra domi x milia equitum, foris autem 5 milia. / Rex Noruegiae quam dominus est magnae patriae et proprii sed pauperis ut supra domi $\mathrm{x}$ milia equitum, foris autem 5 milia. / Rex Hispaniae pari modo propter assidua bella ut supra domi xxx milia equitum, foris autem 15 milia. / Rex Portusgalliae pari modo propter multa bella ut supra domi vi milia equitum, foris autem 3 milia. / <Dux> Rex Britaniae pari modo propter bella plurima diminutur ut supra domi viii milia equitum, foris autem 4 milia. /

[14] Magister sancti Jacobi cum omni suo conatu ut supra domi equitum iiii milia, foris autem 2 milia. / Dux Burgundiae qui prius nutrisset domi c milia equitum, nunc pari modo ut supra domi 30 milia, foris 15 milia. / Rex Renatus ut supra domi equitum vi milia, foris autem 3 milia. / Dux Sabaudie ut supra domi equitum viii milia, foris autem 4 milia. / Marchio Montisferrati ut supra domi equitum $m$ ii milia, foris autem 1000. / Dux Mediolani ut supra domi equitum $\mathrm{x}$ milia, foris autem 5 milia. / Dominum Venetorum ut supra domi equitum $\mathrm{x}$ milia, foris autem 5 milia. / Marchio Mantuanus ut supra domi equitum ii milia, 1000. / < Dux > Marchio Ferrariensis ut supra domi equitum ii milia, foris autem 1000. / Communitas Bononiensis ut supra domi equitum ii milia, foris 
autem 1000. / Senenses ut supra domi equitum ii milia, foris autem 1000. / Summa horum est equitum peritorum in armis 101 milia. / Lucenses ut supra domi equitum ii milia, foris autem 1000. / Florentini ut supra domi equitum iiii milia, foris autem 2 milia. / <Item propter alumen> Summus pontifex pari modo cum omni suo potentatu et redditibus domi ut supra vi equitum milia, foris autem 3 milia. / Genuenses ut supra domi equitum iiii milia, foris autem 2 milia. /

\section{(f. 227r)}

[15] Rex Aragonum cum suo regno Neapolitano et Sicilia ut supra domi equitum xii milia, foris autem 6 milia. / Barchinonenses cum omnibus communitatibus caeteris computatis principibus et dominis totius Catalonie et / Valentiae et Nauarrae domi equitum ut supra milia xii, foris autem 6 milia. / Principes regni Neapolitani omnesque potentes viri ut supra domi equitum vi milia, foris autem 3 milia. / Domini omnes marchie, patrimonii, ducatus et Romandiolae ut supra domi equitum iiii milia, foris autem 2 milia. / $<$ Tota> Alemannia tam spiritalium quam temporalium principum communitatumque et civitatum liberarum Altae et / Bassae Alemanniae cum ipso etiam imperatore cum omni potentatu ut supra domi equitum lx milia, foris 30 milia. / Rex Hungariae et Bohemiae ut supra domi equitum milia lxxx, foris autem 40 milia./ Magnus Prutenorum magister prius nutrisset equitum L milia domi, nunc domi ut supra xxx milia, foris 15 milia. / Rex Poloniae cum duce Vitollo ut supra domi equitu $m \mathrm{~L}^{\text {ta }}$ milia, foris autem 25 milia. /

[16] Daci cum omnibus suis potentatibus ut supra domi equitum $\mathrm{xx}$ milia, foris autem 10 milia. / Morea sive Peloponnesus tota ut supra domi equitum xx milia, foris autem 10 milia. / Albania, Croatia, Sclavonia, Seruia, Rhasia, Bosna ut supra domi xxx milia, foris autem 15 milia. / Rex Cypri ut supra domi milia equitum iiii, foris autem 2 milia. / Dux Archipelagi ut supra domi milia equitum ii, foris autem 1000. / Magnus preceptor Rhodi domi equitum iiii milia, foris autem 2 milia. / Dominus Mitilenes domi equitum ii milia, foris autem 1000. / Imperator Trapezundae ut supra domi equitum xxx milia, foris autem 15 milia. / Rex Georgioniae ut supra domi equitum x milia, foris autem 5 milia. / Summa equitum peritorum in armis centum lxxxxii milia et d milia, 500. / Summa summarum omnes equites christianorum: 300 milia lanciae, c milia / divisae ut supra prenotatum est, quibus sunt necessarii 36 milliones. 1092. /

[17] Turchus ad nutrum suum in domo sua potest nutrire equitum $\mathrm{cccc}$ milia robustorum et peritorum in armis / quos ita disponet cum res geretur contra christianos. Equitum cc milia manebunt circa / ripas Danubii versus Graeciam ut nulli christiano pareat transitus. Nam, attentantibus / christianis transitum in Graeciam, in ipso transitu profligaerentur propter ea quam ordinem in transmeando / non possent conseruare, Turchi autem ordinati permanerent. Equitum item c milia Turchorum / constituerentur ad tutelam in provincia Thessalonicensi ibi ii sunt duo montes Graeciam diuidentes / ab Albania inter quos jacet uallis latitudinis milium passuum xviii. Et ibidem Turchi unam / ducerent fossam ut tentantes transire christianos constitutis ibi castellis i bastitis et / propugnaculis cum bombardis scloppetisque et caeteris missilibus telis ab eo quoque aditu cercerent. /

[18] Versus mare constituerent $\mathrm{L}^{\text {ta }}$ milia equitum qui in littoribus maris permanerent ubicumque / est facilis egressus in terram, quibus resistentibus 
christiani non possent aquari prout factum / ostendit experimentum. A latere uero Turchiae in littoribus maris sicubi est commodus / descensus $\mathrm{L}^{\text {ta }}$ etiam equitum milia locarentur, qui nemine $m$ paterentur in terram egredi / quod, si quis auderitior foret aut egressus, milittus occideretur aut captivaretur. / Et eo modo statuum suum omnem poneret in tuto solus ipse contra omnem christianam potentiam. / Nam ipse ad sui defensionem sibi sufficit non facientibus christianis plus uno exercitu. / Turchus collocaret sua cccc milia equitum omnia aduersus illum unum exercitum sine autem / duos aut plures exercitus facerent. Turchus idem faceret quod si classem christiani arma/ rent terrestre $m$ exercitum oporteret diminuere et ita Turchus suis rebus predicto modo prouideret. I

[19] Hae sunt difficultates christianorum. Ego non cognosco ullum capitaneum qui sciat gubernare lanceas c / milia, et si fuerent plura capita discordarent. Unus autem solus essere posse non videtus / sit non oportet unius alicuius nationis. Si sit Hungarus, Francigenae, Anglici, Hispani, / Burgundiones, Alemannici, Italici nolent essere sed eius imperio, dicent se illo capitaneo / essere digniores et non minus eo scire gubernare quae res erit pessima. Idem de caeteris fiet / quod si etiam omnes fideles in eo conueniant restant hae in supra difficultates: volunt delicate / uiuere bonaque vina habere. Quibus rebus deficientibus statim aegrotant et pereunt sed que oriuntur / discordiae et dissipatur exercitus nisi etiam dormiant sed recto infirmantur ac moriuntur. /

\section{(f. 227v)}

[20] Equi etiam christianorum sunt delicati: uoluunt stabulati et ideo spolia, auena, faeno, insirata paleis, humo, stoa / minibus ne aliis pabulari; aliter minime quolibet incommodo in languerem et mortem cadunt. / Qui immo etiam dictis omnibus rebus optato succedenbus christianis non querint plus triennio in militia / foris durare. Totum namque caeterarum omnium provintiorum aurum necessario conflueret in Hungariam / aut ubi exercitus foret pro victu stipendiis, qui suae cuiusque gentis et cum undique exhaustum / thesauru $m$ acciderit in una $m$ t $a$ men patriam pro necessariis usibus comportari. Caeteri omnes / post triennium christiani nec exercitum possent extra prouintias alere nec se ipsos am / plius tueri quo circa opus est ut dominus donet potentiam christianis cum sapientia. / Exemplum dicti huius mei capi potest ex ultimo bello Lombardiae: nam haec urbis Taruisium, / Padua, Vincentia unum denarium non henbant. In concilio praeterea Basiliensi quis nescit / quantum aurum illuc sit conuectum, caeterae sane prouintiae tanto minus pecuniarum hunere. /

[21] Commoditates Turchorum contra fideles hae quidem sunt. Solus ipse cccc milia equitu $m$ gubernabit, / est non doctus et ad id agendum promptus videtur hoc illi sturpi innatum essere ac naturale / ut sapienter imperent hic sane Mahmetus disciplinam militarem ab anno aetatis suae / duodecimo ingressus semper usque in praesentem diem exerciut habetque nunc annos sex et $\mathrm{xx}^{\mathrm{ti}} . /$

[22] Nulla uero diuisio in eius exercitu quam solus dominus est, nullum se ipso superiorem respicietis / essere potest, subditos tamen suos ducit dicto illius audientes. Gens illa non est ita deliciosa: / aquam potant pro vino, 
solum nivosum ipsis est cubile, neque ullis difficultatibus huiusmodo / aegrotant solis etiam ardentis patientes sunt. Pari modo eorum equi iacent in niuibus, / neque ende fiunt debiliores aestiam etiam tolerant absque offensione. Aurum et argentum / eius nequit exhauriri expenditur non inter suos in propria remanens patria / un um comportantur ei omnia victui necessaria quam res facit ut possit perdurare. /

[23] Nihil esset igitur hoc tempore christianis utilius quam in hoc consilio prestare uti possidetis et talibus / pactis concordiam inire, ut qui possidet possideat quippe securitate et ocio fietur, / uoluptatibus Turchus dederetur gaudens luxus ac conuiniorum mollicie animoque similiter in seruiens / ac corpori eo pacto uim omnem animi eneruaret effaeminaretque potatonibus ac / venereis deditur libidinibus. Illum uero sui quoque talibus in studiis imitarentur, / ita fieret eiusmodi remissione in dies ignanior laborumque ac periculorum osor / et impatiens atque turpium desideriarum denique captivus ac servus. / Tunc demum ubi ille satis viluisset elanguissetque darent operam suo tempore / christiani ut parvo negotio absque omni discrimine a missa recuperarent. / Quod ille dignetur concedere, qui est benedictus in secula. Amen. Finis.

Fecha de recepción del artículo: julio 2014

Fecha de aceptación y versión final: mayo 2015 